\title{
Bibliometric Analysis of Game-Based Methodology in Environmental Education
}

P.D. Franco-Caballero pablo.franco@uma.es G.E.Sotorrío-Sánchezｇloria.sotorrio@uma.es A. Matas-Terrón $\quad$ amatas@uma.es

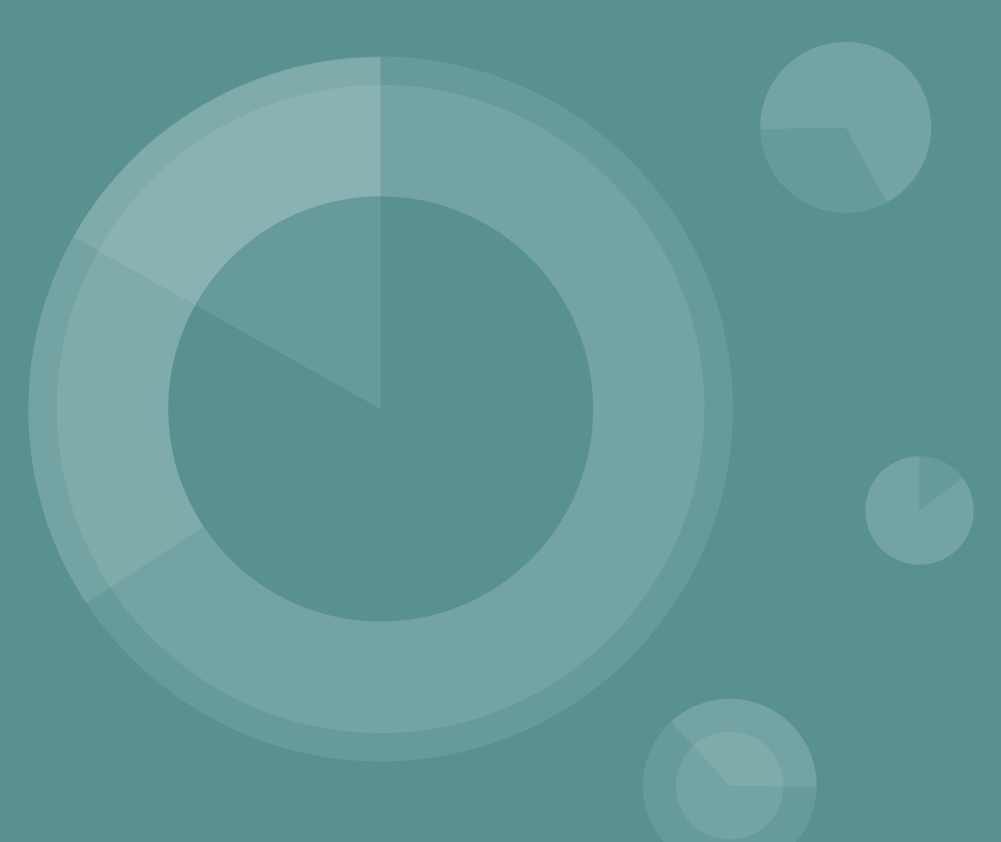




\section{Introduction}

(2)

Environmental Education is the educational process that relates the individual to his or her natural and artificial environment, considering all the elements that it affects and is affected by, such as population density, pollution, resource use, urban/rural planning, etc.

One of the trends that is obtaining the best results for teaching in environmental education is the use of game philosophies for its development.

A search of the word "gamification" in Scopus shows that $\mathbf{2 1 3}$ papers were published in 2013 and 1193 papers in 2020. This shows the growing interest in the subject in the academic field. In this sense, Environmental Education is also taking on this interest. 


\section{Objective}

6

"To facilitate the understanding of the field of study of environmental education that uses gamification as a methodology, making visible both those topics considered relevant and those that can serve as a research niche. For this reason, we proposed the creation of representations that could serve as a starting point for future interested researchers through bibliometric analysis." 
ICERi ${ }_{2021}$

\section{Methodology \\ Methodology}




\section{Bibliographic collection}

Collected from the Web of Science (WoS) Scopus database in June 2021.

Syntax: (KEY(environmental AND education)) AND (gamification OR gaming)

The collection was 228 documents, dated between 1972 and 2021.

\section{R Studio}

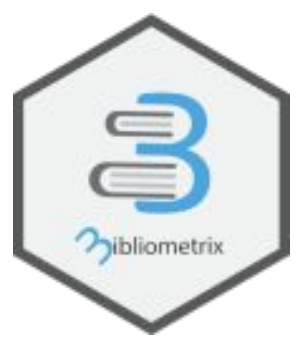




\section{Analysis}

Cluster Analysis

The references of each document are related and when they coincide, they are "linked". The degree of linkage can be calculated based on whether they share the same reference.

Conceptual Analysis

The relationship between the keywords of the documents in the collection are evaluated. 
- iCERi

Results 


\section{Cluster Analysis}

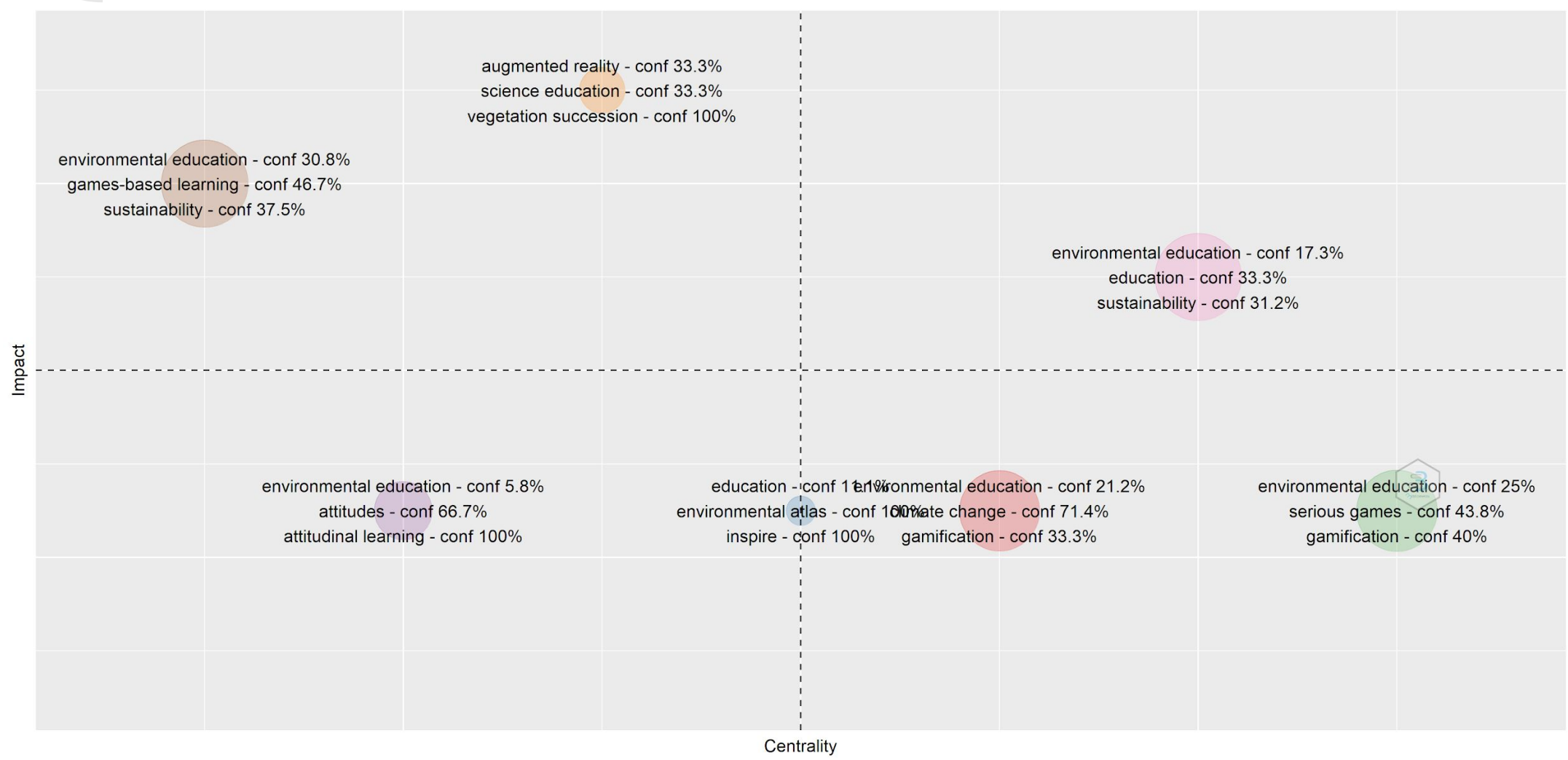




\section{Conceptual Analysis}

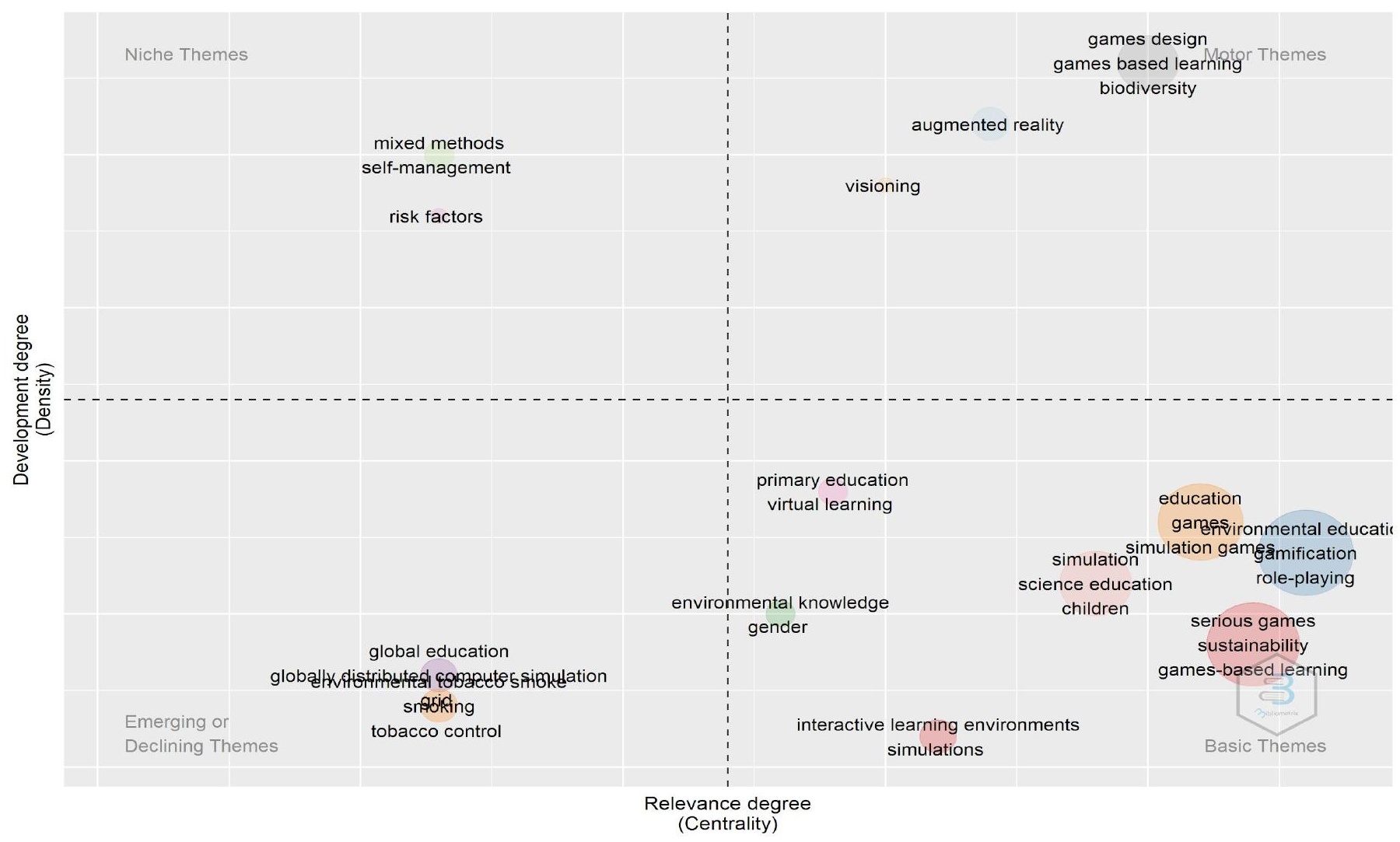


[CERi ${ }_{2021}$

Conclusions

- ICERi ${ }_{2021}$

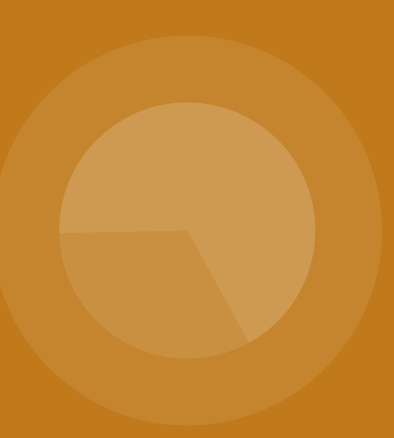

(1)

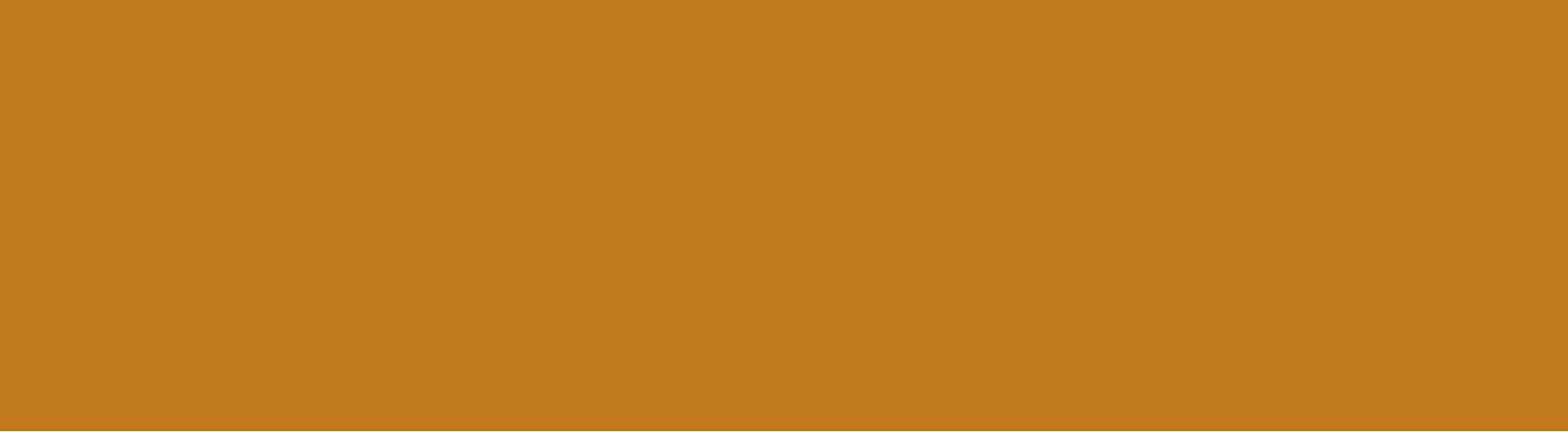




\section{Conclusions}

According to Cluster Analysis:

Q

The themes are related in such a way that the links between game-based learning, probably through serious games, and sustainability within the environmental theme seem to be more relevant.

According to Conceptual Analysis:

The themes are related in such a way that the links between game-based learning, probably through serious games, and sustainability within the environmental theme seem to be more relevant. 


\section{Bibliometric Analysis of Game-Based Methodology in Environmental Education}

P.D. Franco-Caballero pablo.franco@uma.es G.E.Sotorrío-Sánchezｇloria.sotorrio@uma.es A. Matas-Terrón $\quad$ amatas@uma.es

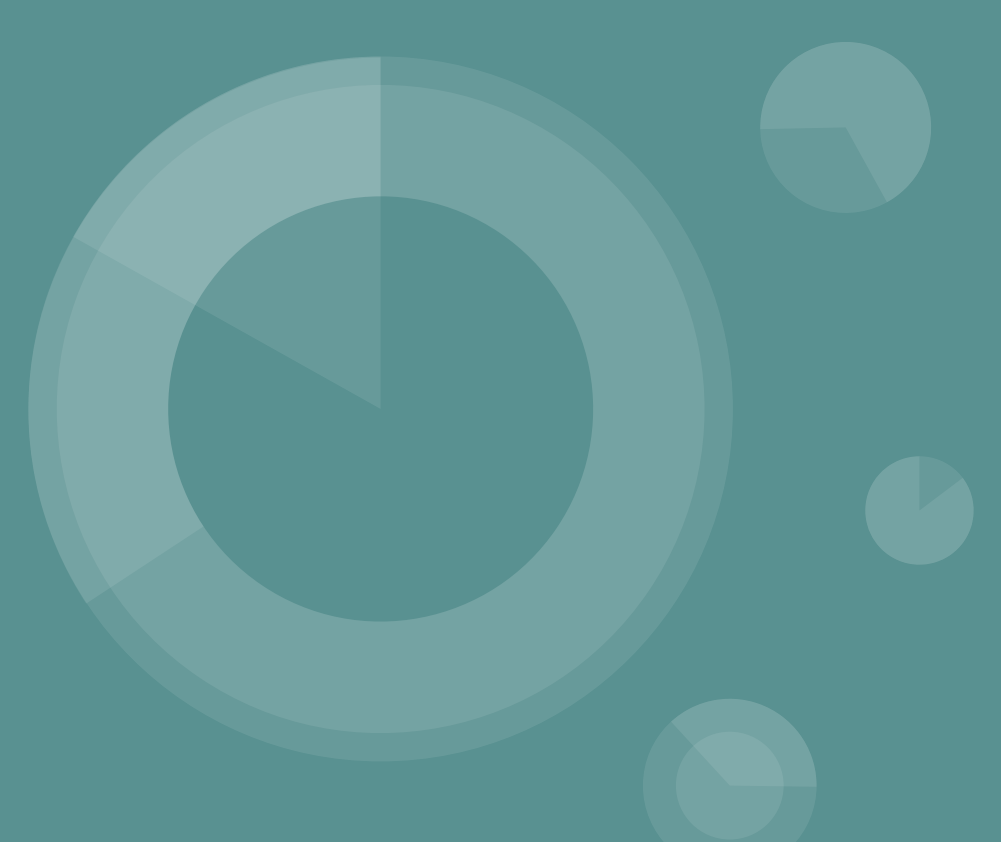

